groups considered to be highly vulnerable to infection, including MSM. This present study was conducted to answer key questions with a view to gaining a better understanding of the reality of MSM with regard to HIV/AIDS at AAS. The results are to contribute to the development of an appropriate response strategy.

Methodology The study's aim was to identify possible paths of action and strategies pertaining to MSMs' access to STI/AIDS care, treatment and prevention services at AAS. The study was based on a questionnaire focusing on MSMs' contextual environment and the socio-behavioural factors that determine their vulnerability to STIs and HIV.

Principle Results The questionnaire was administered among 84 MSM at the Centre Oasis, at places where they gather or at their homes. Of those men, 13\% are between 17 and 19 years old; $33 \%$ between 20 and 24; 25\% between 25 and 29; and $29 \%$ age 30 and over. $78 \%$ are single; $5.2 \%$ have a girlfriend; and $16.8 \%$ are married to a woman. Survey participants' first sexual experience was with an MSM friend in $70.5 \%$ of cases; with an unknown partner in $18.3 \%$ of cases; and with classmates in $11.2 \%$ of cases. $89.4 \%$ of the MSM surveyed consented to their first sexual encounter with another man; their motivation was-sexual desire (68\%); curiosity (12\%); need of money (11\%); need of a service $(9 \%) .47 \%$ used a condom during that first sexual encounter, from which 13\% emerged with injuries and bleeding. $81 \%$ of those surveyed maintain parallel sexual relationships with women. $83 \%$ are aware of HIV; 69\% gonorrhoea; $61 \%$ syphilis; and they do not master the other STIs. $97 \%$ know that unprotected sex is high-risk; $83.4 \%$ know about relevant risks from contaminated objects, and $58.1 \%$ are familiar with relevant risks from blood transfusions. $61.1 \%$ systematically use condoms during sex with other men.

Conclusion This exploratory study has allowed us to gain a number of insights. We will now use this data as a basis for improving the services we offer to MSM.

Abstract P1-S2.38 Table 1 Incidence rates of urethral discharge among MSM coming into the Avahan clinics

\begin{tabular}{|c|c|c|c|c|c|}
\hline Characteristics & $\begin{array}{l}\text { IR per } 100 \text { PY } \\
\text { Incidence rate } \\
\text { per } 100 \\
\text { person years }\end{array}$ & $\begin{array}{l}95 \% \mathrm{Co} \\
\text { Lower }\end{array}$ & Upper & HR & p Value \\
\hline \multicolumn{6}{|l|}{ Typology (Self-identity) } \\
\hline Kothi (Receptive) & 6.4 & 6.1 & 6.6 & \multicolumn{2}{|l|}{ Reference } \\
\hline Double Decker (Versatile) & 7.3 & 6.9 & 7.6 & & \\
\hline Panthi (Penetrative) & 14.5 & 14 & 15.2 & 1.04 & $<0.001$ \\
\hline \multicolumn{6}{|c|}{ Number of years in commercial sex } \\
\hline$<5$ years & 5 & 4.5 & 5.6 & \multicolumn{2}{|l|}{ Reference } \\
\hline $2-5$ years & 4.6 & 4.1 & 5.2 & & \\
\hline$>1$ year & 14.9 & 14.5 & 15.3 & 4.29 & $<0.001$ \\
\hline \multicolumn{6}{|l|}{ Number of clients per week } \\
\hline$<5$ clients per week & 2.8 & 2.5 & 3.2 & \multicolumn{2}{|l|}{ Reference } \\
\hline $6-10$ clients per week & 3.6 & 3.1 & 4 & & \\
\hline$>10$ clients per week & 6.7 & 5.9 & 7.6 & 1.62 & $<0.001$ \\
\hline \multicolumn{6}{|l|}{ Self-reported condom use } \\
\hline Condom used in last sex & 4.3 & 4.1 & 4.4 & \multicolumn{2}{|c|}{ Reference } \\
\hline No condom used in last sex & 15 & 14.5 & 15.4 & 2.28 & $<0.001$ \\
\hline \multicolumn{6}{|c|}{ Cefixime and azithromycin (Presumptive treatment-PT given in the first three clinic visits) } \\
\hline Given PT & 7.9 & 1.7 & 1.9 & \multicolumn{2}{|c|}{ Reference } \\
\hline Not given PT & 11.1 & 20.8 & 21.9 & 2.79 & $<0.001$ \\
\hline \multicolumn{6}{|c|}{ Number of visits per year to the clinic } \\
\hline More than 8 visits per year & 0.5 & 0.4 & 0.6 & \multicolumn{2}{|l|}{ Reference } \\
\hline $7-8$ visits per year & 0.8 & 0.6 & 0.9 & & \\
\hline $5-6$ visits per year & 0.9 & 0.7 & 1 & & \\
\hline $3-4$ visits per year & 1.3 & 1.28 & 1.5 & & \\
\hline $1-2$ visits per year & 27.6 & 27 & 28.3 & 0.85 & $<0.001$ \\
\hline
\end{tabular}

\section{P1-S2.39 CHARACTERISTICS OF LYMPHOGRANULOMA VENEREUM (LGV) INFECTION AMONG HOMOSEXUAL MEN IN MELBOURNE.}

doi:10.1136/sextrans-2011-050108.96

\section{Bissessor. Melbourne Sexual Health, Carlton, Australia}

Background Lymphogranuloma venereum (LGV) has re-emerged among men who have sex with men (MSM) internationally. Previous cases among MSM in Australia have been reported. We aimed to characterise a series of LGV cases seen at the Melbourne Sexual Health Centre.

Methods We reviewed all cases of LGV seen at the Melbourne Sexual Health Centre between 2005 and 2010. During this period MSM who were diagnosed with rectal chlamydia using strand displacement assay were routinely questioned about symptoms of proctitis using a symptom check list. Those with symptoms of proctitis had specimens forwarded for Chlamydia trachomatis omp1 genotyping. Genotyping of chlamydia-positive first void urine and penile ulcers in MSM was undertaken on selected MSM based on clinical presentation.

Results During the study period, of 292 chlamydia positive anorectal specimens that were genotyped, $21(7.2 \%)$ tested positive for LGV. Of the eight chlamydia positive urine or penile specimens genotyped, four were positive for LGV. There was also one case of an inguinal bubo that tested LGV positive from aspirated pus. In all cases L2 or L2b type was isolated. Of the 25 cases of LGV, 18 (72\%) were in HIV positive men. Of the 21 men who had ano-rectal LGV, all had ano-rectal symptoms, namely-ano-rectal pain (71\%), anal discharge (62\%) and/or rectal bleeding (52\%). All but one of the LGV infected men received at least a 3 -week course of doxycycline $100 \mathrm{mg}$ twice daily. Two men with ano-rectal LGV remained LGV positive on follow-up when tested 3 months later. Both these patients were noted to have had unprotected sex following initial treatment, hence, it is unclear whether this was due to treatment failure or reinfection.

Conclusions LGV continues to be seen among MSM in Melbourne presenting with proctitis. Genotyping of anal chlamydia infections has been useful in distinguishing LGV from the more common nonLGV chlamydial infections, therefore ensuring appropriate antibiotic therapy and follow-up are instigated.

\section{P1-S2.40 HIV AND SYPHILIS COINFECTION AMONG MEN WHO HAVE SEX WITH MEN, 34 STATES, USA-2009}

doi:10.1136/sextrans-2011-050108.97

J Su. Centers for Disease Control and Prevention, Atlanta, USA

Background During the early 2000s, reports of the re-emergence of syphilis among men who have with men (MSM) in the USA described a high prevalence of HIV coinfection in different localities, often among middle-aged men. Since 2001, syphilis has increased among men in younger age groups. Here, we present a description of HIV coinfection among MSM of different races and ethnicities with primary and secondary syphilis across multiple states during 2009. Methods We reviewed data reported to CDC from states in the USA that reported HIV coinfection status for at least $70 \%$ of cases of primary and secondary $(P \& S)$ syphilis during 2009. These data originated from $\mathrm{P} \& \mathrm{~S}$ syphilis patient interviews and included census region, sex, sex of sex partner, race, ethnicity, and HIV infection status. Prevalence of coinfection was calculated using coinfected patients as the numerator, and all $\mathrm{P} \& \mathrm{~S}$ syphilis patients who were asked about their HIV status as the denominator.

Results 34 states and Washington, DC from all regions of the USA met inclusion criteria, accounting for $82 \%$ of all $\mathrm{P} \& \mathrm{~S}$ syphilis in the 
Abstract P1-S2.40 Table 1 HIV coinfection among men who had sex with men (MSM) in the past 12 months with primary and secondary (P\&S) syphilis, by age group, race, and ethnicity-34 states, 2009

\begin{tabular}{|c|c|c|c|c|c|c|c|c|}
\hline \multirow[b]{2}{*}{$\begin{array}{l}\text { Age group, } \\
\text { years }\end{array}$} & \multicolumn{2}{|l|}{ Black MSM } & \multicolumn{2}{|c|}{ Hispanic MSM } & \multicolumn{2}{|l|}{ White MSM } & \multicolumn{2}{|l|}{ Other MSM } \\
\hline & $\begin{array}{l}\text { With P\&S } \\
\text { syphilis, no. }\end{array}$ & $\begin{array}{l}\text { HIV coinfected, } \\
\text { no. }(\%)\end{array}$ & $\begin{array}{l}\text { With P\&S } \\
\text { syphilis, no. }\end{array}$ & $\begin{array}{l}\text { HIV coinfected, } \\
\text { no. }(\%)\end{array}$ & $\begin{array}{l}\text { With P\&S } \\
\text { syphilis, no. }\end{array}$ & $\begin{array}{l}\text { HIV coinfected, } \\
\text { no. }(\%)\end{array}$ & $\begin{array}{l}\text { With P\&S } \\
\text { syphilis, no. }\end{array}$ & $\begin{array}{l}\text { HIV coinfected, } \\
\text { no. }(\%)\end{array}$ \\
\hline $15-19$ & 219 & 77 (35\%) & 62 & $7(11 \%)$ & 49 & $11(22 \%)$ & 10 & $1(10 \%)$ \\
\hline $20-24$ & 728 & 377 (52\%) & 252 & $76(30 \%)$ & 227 & $61(27 \%)$ & 41 & $9(22 \%)$ \\
\hline $25-29$ & 485 & $315(65 \%)$ & 258 & $113(44 \%)$ & 288 & $115(40 \%)$ & 48 & $20(42 \%)$ \\
\hline $30-34$ & 296 & $201(68 \%)$ & 202 & $102(50 \%)$ & 272 & $140(51 \%)$ & 39 & $18(46 \%)$ \\
\hline $35+$ & 676 & $454(67 \%)$ & 487 & $315(65 \%)$ & 1512 & $854(56 \%)$ & 93 & $51(55 \%)$ \\
\hline Total & 2404 & 1424 (59\%) & 1261 & 613 (49\%) & 2348 & 1181 (50\%) & 231 & 99 (43\%) \\
\hline
\end{tabular}

USA during 2009 and $77 \%$ of estimated HIV diagnoses during 2008. Of 6501 men who had sex with men (MSM) in the past 12 months with P\&S syphilis, 6346 (98\%) were asked about HIV status-53\% were coinfected with HIV, $38 \%$ were not coinfected, $1 \%$ refused to disclose their status, and $8 \%$ did not know their status. Across all regions, prevalence of HIV coinfection among MSM with P\&S syphilis was high (51-55\%, depending on region). Black MSM with P\&S syphilis were younger than other MSM with P\&S syphilis-39\% of black MSM with P\&S syphilis were under 25 years old (Hispanic MSM-25\%, white MSM-12\%, other MSM-22\%) (see Abstract P1-S2.40 Table 1). Compared to 15-19-year old and 20-24year old MSM with P\&S syphilis of other races and ethnicities, black MSM were more likely to be HIV coinfected (RR 15-19-year old $=2.2, \mathrm{p}<0.001$; RR 20-24-year old $=1.8, \mathrm{p}<0.001)$. Prevalence of HIV coinfection increased with age; black MSM with P\&S syphilis reached the highest prevalence of HIV coinfection at an earlier age than MSM with P\&S syphilis of other races and ethnicities.

Conclusion Regardless of race, ethnicity or region, MSM with P\&S syphilis had high rates of HIV coinfection. Interventions at young ages are urgently needed to prevent HIV and P\&S syphilis among MSM.

\section{P1-S2.41 SENTINEL SURVILLANCE FOR PHARYNGEAL CHLAMYDIA AND GONORRHOEA AMONG MEN WHO HAVE SEX WITH MEN - SAN FRANCISCO, 2010}

doi:10.1136/sextrans-2011-050108.98

${ }^{1} \mathrm{~J}$ Park, ${ }^{2} \mathrm{~J}$ Marcus, ${ }^{2} \mathrm{~K}$ Bernstein, ${ }^{2} \mathrm{M}$ Pandori, ${ }^{2} \mathrm{~A}$ Snell, ${ }^{2} \mathrm{~S}$ Philip. ${ }^{1} \mathrm{UC}$ Berkeley, Berkeley, USA; ${ }^{2}$ San Francisco Department of Public Health, USA

Background Although a potentially important route for transmission, limited data exist on the burden of pharyngeal chlamydia (CT) and gonorrhoea (GC) among men who have sex with men (MSM). The San Francisco Department of Public Health has recommended nucleic acid amplification test (NAAT)-based pharyngeal screening for MSM since 2005. We examined pharyngeal CT and GC among MSM participating in the STD screening program in 2010.

Methods MSM seeking services at a variety of clinical sites provided clinician-collected pharyngeal specimens for APTIMA Combo 2 testing. The prevalence of pharyngeal CT and GC was estimated at five sentinel sites-the municipal STD clinic, a gay men's health clinic, an HIV care clinic, an HIV testing site, and primary care clinics supported by the San Francisco Department of Public Health. Positivity for each infection was calculated as the number of positive tests divided by the number of testers with corresponding CIs. Additionally, we calculated positivity and OR to determine whether the prevalence of pharyngeal CT and GC differed by HIV status among patients tested at the municipal STD clinic.

Results In 2010, over 12000 pharyngeal specimens were tested for an overall CT positivity of $1.69 \%$ (95\% CI 1.47 to 1.93$)$ and GC positivity of $5.76 \%$ ( $95 \%$ CI 5.36 to 6.19 ). At the five sentinel sites, pharyngeal CT positivity ranged from $1.10 \%$ (HIV testing site) to $2.28 \%$ (STD clinic); pharyngeal GC positivity ranged from $3.4 \%$ (HIV testing site) to $7.01 \%$ (STD clinic). For tests conducted at the STD clinic among HIV-uninfected testers, pharyngeal CT positivity was $1.57 \%$ (95\% CI 1.11 to 2.15 ) and pharyngeal GC positivity was $7.02 \%$ (95\% CI 6.03 to 8.11). Among HIV-infected testers, the pharyngeal CT and GC positivity were $4.06 \%$ (95\% CI 2.92 to 5.49 ) and $6.99 \%$ (95\% CI 5.48 to 8.76), respectively. HIV-infected testers were more likely to have a positive pharyngeal CT test compared with HIV-uninfected testers (OR 2.65, 95\% CI 1.65 to 4.27); there were no differences in pharyngeal GC positivity between HIVinfected and HIV-uninfected testers at the STD clinic.

Conclusion Sentinel surveillance data indicates that there is a substantial burden of pharyngeal CT and GC infections among MSM in San Francisco. Identification and treatment of pharyngeal infections could prevent ongoing transmission of these bacteria. Increasing access to NAAT-based pharyngeal screening should be a public health priority.

\section{P1-S2.42 STI PREVALENCE AND CONDOM USE IN MEN WHO HAVE SEX WITH MEN ATTENDING STI SERVICES, HONDURAS 2010}

doi:10.1136/sextrans-2011-050108.99

${ }^{1} \mathrm{~F}$ Tinajeros, ${ }^{1} \mathrm{~N}$ Artiles, ${ }^{1} \mathrm{~N}$ Farach, ${ }^{2} \mathrm{~L}$ Castro, ${ }^{2} \mathrm{~V}$ Maradiaga, ${ }^{3} \mathrm{~A}$ Sevilla, ${ }^{4} \mathrm{~S}$ Mendoza, ${ }^{5} \mathrm{M}$ Urquia, ${ }^{5} \mathrm{H}$ Galindo, ${ }^{6} \mathrm{G}$ Paz-Bailey. ${ }^{1}$ TEPHINET, Tegucigalpa, Honduras; ${ }^{2}$ Alonso Suazo Clinic, Tegucigalpa, Tegucigalpa, Honduras; ${ }^{3}$ Miguel Paz Barahona Clinic, San Pedro Sula, San Pedro Sula, Honduras; ${ }^{4}$ STI National Laboratory, Honduras, Tegucigalpa, Honduras; ${ }^{5}$ Ministry of Health, National AIDS Program, Tegucigalpa, Honduras; ${ }^{6}$ TEPHINET, Del Valle University of Guatemala, Guatemala

Background Men who have sex with men and the transgender population have the highest prevalence of HIV in Honduras. Specialised services for MSM were established at three public clinics in San Pedro Sula, La Ceiba and Tegucigalpa, with the objective of improving STI management and access to HIV testing and counselling among MSM and transgender populations. STI and HIV testing and management were strengthened at three STI clinics in early 2010. Health workers were trained on HIV/STI services, including counselling and reducing stigma and discrimination.

Methods Discussions with MSM organizations were carried out to determine the type of clinical and counselling services as well as a referral strategy for MSM. A standardised form was designed and implemented to collect key clinical, laboratory and behavioural indicators and entered into an electronic system in Epi-Info. The diagnostic tests offered at no charge were-rapid test and ELISA for HIV, PACE II for Chlamydia trachomatis and Neisseria gonorrhoeae, and RPR with TPPA for syphilis. All men attending the clinics in 2010 were included in this analysis. 